\title{
SINERGIA
}

REVISTA DO INSTITUTO DE CIÊNCIAS ECONÔMICAS, ADMINISTRATIVAS E CONTÁBEIS (ICEAC)

\section{ANÁLISE ECONOMÉTRICA DA INFLUÊNCIA DA TAXA DE CÂMBIO E DA RENDA EXTERNA SOBRE AS EXPORTAÇÕES DOS PRODUTOS BÁSICOS DO ESTADO DO RIO GRANDE DO SUL (2001-2018)}

\author{
LETÍCIA FAVARETTO \\ JULIANA FAVARETTO"* \\ ELISANGELA GELATTI** \\ DANIEL ARRUDA CORONEL \\ CLAITON ATAÍDES DE FREITAS \\ LEONARDO SANGOI COPETTI**+
}

\section{RESUMO}

O objetivo deste trabalho foi o de mensurar a influência da taxa de câmbio e da renda externa sobre as exportações de produtos básicos do Estado do Rio Grande do Sul (RS) para o período de janeiro de 2001 a outubro de 2018. Os dados foram coletados no site IPEADATA e no site Internacional Financial Statistics do Fundo Monetário Internacional (FMI/IFS). Para tanto, utilizou-se o Modelo Vetorial de Correção de Erros (VECM). Os resultados indicaram que a elasticidade da renda externa é muito superior à elasticidade da taxa de câmbio, inferindo-se que as exportações gaúchas de produtos básicos respondem melhor a uma variação na renda externa do que à da taxa de câmbio. Assim, o crescimento da renda mundial e, consequentemente, o aumento da demanda fazem com que as exportações não sejam tão dependentes da taxa de câmbio.

Palavras-Chaves: Modelo Vetorial De Correção De Erros (VECM). Balança Comercial. Rio Grande do Sul.

\section{ABSTRACT}

The aim of this paper was to measure the influence of the exchange rate and foreign income on exports of basic commodities of Rio Grande do Sul state (RS), for the period from January, 2001 to October, 2018. The data were collected in the sites IPEADATA and International Financial Statistics of International Monetary Fund (IMF/IFS). In this sense, we used the Vector Error Correction Model (VECM). The results indicated that the elasticity of foreign income is much higher than the elasticity of the exchange rate, inferring that the basic commodities exports of Rio Grande do Sul respond better to a variation of foreign income than the exchange rate. Thus, the growth of world income, and consequently the increase of demand makes that the exports are not so dependent on the exchange rate.

Keywords: Vector Error Correction Model (VECM); Trade Balance; Rio Grande do Sul.

Recebido em: 13-05-2020 Aceito em: 25-06-2020

\section{INTRODUÇÃO}

O comércio internacional possui um papel importante para o desenvolvimento econômico e social de um país, pois, além de gerar divisas e crescimento econômico, contribui para a diversificação da economia nacional e cria oportunidades para a geração de emprego. Ao longo dos anos, o Brasil vem aumentando significativamente suas relações de comércio internacional. Isso pode ser diagnosticado olhando alguns números da balança comercial brasileira, pois, em 2001, o país exportou, aproximadamente, US $\$ 58,1$ bilhões e importou $\cup \$ 55,4$ bilhões, resultando em superávit balança comercial de U\$2,7 bilhões; já em

\footnotetext{
Discente do Curso de Graduação em Ciências Econômicas da Universidade federal de Santa Maria e Bolsista de Iniciação Científica (PIBIC) do CNPq.

"* Discente do Curso de Graduação em Ciências Econômicas da Universidade federal de Santa Maria e Bolsista de Iniciação Científica (PIBIC) do CNPq.

${ }^{* *}$ Doutoranda em Economia pela Esalq-USP, Mestra em Economia e Desenvolvimento pela Universidade Federal de Santa Maria.

*u* Doutor em Economia Aplicada pela Universidade Federal de Viçosa (UFV); mestre em Agronegócios pela Universidade Federal do Rio Grande do Sul (UFRGS); especialista em Estatística e Modelagem Quantitativa pela UFSM; bacharel em Administração pela Universidade do Vale do Rio dos Sinos (Unisinos) e em Ciências Econômicas pela Universidade Federal de Santa Maria. Professor Associado do Departamento de Economia e Relações Internacionais da Universidade Federal de Santa Maria. E-mail: daniel.coronel@uol.com.br

“ Docente do Curso de Graduação em Ciências Econômicas e do Programa de Pós-Graduação de Economia e Desenvolvimento da Universidade Federal de Santa Maria.

"Mestre em Administração pela Universidade Federal de Santa Maria.
} 
2018 , as exportações foram cerca de US $\$ 239,8$ bilhões e a importação de, aproximadamente, US $\$ 181,2$ bilhões, com superávit de US\$58,6 bilhões (MDIC, 2019).

Em relação aos estados brasileiros, no cenário internacional, destaca-se que o Rio Grande do Sul (RS), em 2018, foi o quarto colocado em termos de participação nas exportações brasileiras, exportando cerca de US\$21,0 bilhões, ou $8,8 \%$ do total exportado pelo País. Ao analisar as exportações gaúchas por fator agregado, evidencia-se que o setor de produtos básicos e de baixa intensidade tecnológica é o principal gerador de divisas. Conforme dados do MDIC (2019), nos últimos cinco anos, os produtos básicos tiveram uma participação média de $51 \%$ nas exportações totais do Rio Grande do Sul. Estes dados demonstram a relevância da participação desse estado nas relações de comércio exterior.

Neste sentido, destaca-se que a pauta de exportações do Rio Grande do Sul e de outros estados brasileiros, como Paraná e Mato Grosso, foi fortemente influenciada pela entrada da China no mercado internacional, especialmente a partir dos anos 2000. Ainda nesta perspectiva, a participação das exportações gaúchas, no total das exportações do Brasil para a China, correspondeu a cerca de 10,4\% em média durante os anos de 2017 e 2018 (ATLAS SOCIOECONÔMICO DO RIO GRANDE DO SUL, 2019).

Convém ressaltar que a competitividade das exportações é influenciada por fatores econômicos específicos, e, entre os principais citados pela literatura internacional, destacam-se a renda externa e a taxa de câmbio. Ramalho e Targino (2003, p.2) apontam que as exportações locais elou regionais e a renda externa possuem uma relação direta, ou seja, se ocorrer uma "elevação da renda externa se expande a procura pelos bens comercializáveis do país local e, portanto, causa um efeito positivo nas exportações do país local". Quanto à taxa de câmbio, de forma geral, é apontada como um dos principais determinantes dos fluxos agregados de importação e exportação, e, consequentemente, do desempenho comercial de um país (CARNEIRO, 2014). Sugere-se que o crescimento das economias mundiais (renda externa), em especial dos países da Ásia (Japão, China e Coreia do Sul) e Países Baixos (Holanda), tende a influenciar as exportações do Rio Grande do Sul por se tratar de países parceiros comerciais usuais (MDIC, 2019).

Neste sentido, este estudo busca contribuir na caracterização de um panorama mais atual em relação às exportações de produtos básicos do Rio Grande do Sul, que correspondem a mais de $46 \%$ do total das exportações do estado (MDIC, 2019). Além disso, percebe-se a necessidade de estudos que analisem o impacto das principais variáveis macroeconômicas, como o câmbio e a renda externa, dadas as mudanças macroeconômicas significativas que vêm ocorrendo ao longo dos anos, no cenário nacional (BRAGA; OLIVEIRA, 2018), uma vez que é de conhecimento que esses fatores impactam significativamente as exportações no geral, porém podem não afetar da mesma forma ou com a mesma intensidade as exportações de um produto específico, como o caso, produtos básicos gaúchos.

Assim, este trabalho propõe-se investigar se a renda mundial e a taxa de câmbio foram importantes para o crescimento das exportações de produtos básicos do Rio Grande do Sul entre os anos de 2001 a 2018. Em vista deste objetivo, a hipótese deste trabalho é testar a possível existência de uma relação de longo prazo entre as variáveis (renda externa e taxa de câmbio) sobre o desempenho das exportações de produtos básicos do Rio Grande do Sul. Para alcançar o objetivo proposto, utilizam-se ferramentas de séries temporais, especificamente o Modelo Vetorial de Correção de Erros (VECM), capaz de mensurar o nível de sensibilidade (elasticidade) das variáveis.

\section{SETOR EXTERNO DO RIO GRANDE DO SUL}

O Rio Grande do Sul, em 2018, foi o quarto estado brasileiro que mais exportou, e sua participação foi cerca de $8,8 \%$ (US $\$ 21.038,93$ bilhões) das exportações totais do país, ficando atrás dos estados de São Paulo (US\$23,9 bilhões), Minas Gerais (US\$24,2 bilhões) e Rio de Janeiro (US\$29,7 bilhões) (MDIC, 2019). Já em relação à participação em importações, ficou em quinto (US $\$ 11,2$ bilhões), atrás de Paraná (US $\$ 12,3$ bilhões), Santa Catarina (US $\$ 15,4$ bilhões), Rio de Janeiro (US\$24,0 bilhões) e São Paulo (US $\$ 60,8$ bilhões) (MDIC, 2019) ${ }^{1}$. Destaca-se que, em relação ao ano de 2017 , as exportações gaúchas tiveram um aumento de $18,31 \%$ em 2018 , e as importações aumentaram cerca de $8,8 \%$, neste mesmo período (MDIC, 2019).

Quanto à balança comercial do Rio Grande do Sul, durante o período de 2001 a 2018, ela apresentou várias oscilações, mas manteve-se sempre positiva (Tabela 1). O seu menor saldo foi no ano de 2012 (US\$ 2,4 bilhões), entretanto, recuperou-se e, no ano seguinte, obteve um saldo de US\$ 8,3 bilhões. A balança comercial obteve uma taxa média de crescimento (Tabela 1 ) anual de $3,66 \%$ para o mesmo período. Destaca-se que, no de 2018, a balança comercial gaúcha teve um saldo de US $\$ 9,7$ bilhões, sendo este 0 maior superávit da década.

\footnotetext{
${ }^{1}$ Valores Nominais.
} 
Tabela 1 - Balança Comercial do Rio Grande do Sul de 2001 a 2018 em bilhões (US\$ FOB)

\begin{tabular}{cccc}
\hline Ano & Exportação & Importação & Saldo \\
\hline 2001 & 6.341 .332 .668 & 3.319 .964 .979 & 3.021 .367 .689 \\
\hline 2002 & 6.372 .078 .971 & 2.830 .657 .950 & 3.541 .421 .021 \\
\hline 2003 & 8.009 .358 .402 & 3.472 .652 .578 & 4.536 .705 .824 \\
\hline 2004 & 9.875 .302 .363 & 4.164 .107 .752 & 5.711 .194 .611 \\
\hline 2005 & 10.449 .255 .822 & 4.802 .312 .203 & 5.646 .943 .619 \\
\hline 2006 & 11.723 .860 .234 & 5.856 .023 .077 & 5.867 .837 .157 \\
\hline 2007 & 14.903 .600 .345 & 7.718 .769 .596 & 7.184 .830 .749 \\
\hline 2008 & 18.333 .047 .510 & 10.747 .661 .198 & 7.585 .386 .312 \\
\hline 2009 & 15.200 .632 .346 & 7.255 .540 .298 & 7.945 .092 .048 \\
\hline 2010 & 15.330 .066 .322 & 10.792 .612 .204 & 4.537 .454 .118 \\
\hline 2011 & 19.380 .556 .331 & 13.388 .398 .622 & 5.992 .157 .709 \\
\hline 2012 & 17.328 .522 .067 & 14.880 .588 .960 & 2.447 .933 .107 \\
\hline 2013 & 25.053 .882 .812 & 16.731 .576 .173 & 8.322 .306 .639 \\
\hline 2014 & 18.658 .415 .317 & 14.911 .316 .511 & 3.747 .098 .806 \\
\hline 2015 & 17.512 .591 .102 & 9.991 .555 .819 & 7.521 .035 .283 \\
\hline 2016 & 16.580 .774 .439 & 8.296 .763 .798 & 8.284 .010 .641 \\
\hline 2017 & 17.782 .259 .365 & 9.921 .631 .745 & 7.860 .627 .620 \\
\hline 2018 & 21.038 .929 .353 & 11.280 .006 .566 & 9.758 .922 .787 \\
\hline
\end{tabular}

Fonte: Elaborada pelos autores, com base nos dados MDIC (2019)

As exportações e importações gaúchas apresentaram um crescimento significativo, no período de 2001 a 2018, com uma taxa média de crescimento anual de 6,72\% e 8,88\%, respectivamente. Destaca-se que as exportações gaúchas passaram de US\$6,3 bilhões, em 2001, para US\$21,0 bilhões em 2018. Apesar de apresentar um crescimento, observa-se, nesse período, que, em alguns anos, houve uma queda no valor das exportações, estas justificadas por diversos fatores internos e externos à economia do Rio Grande do Sul, como "a estiagem ocorrida em 2012; dificuldades que surgiram nas exportações destinadas à Argentina; o embargo russo à carne gaúcha; queda na demanda internacional, devido ao ritmo econômico global desaquecido" (CALDAS, 2013, p.52) e a crise internacional de 2008.

Quanto às exportações gaúchas, o ano de 2013 merece destaque, visto que o estado exportou cerca de US $\$ 25$ bilhões, alcançando seu maior pico, um crescimento de 44,3\% (US\$ 7,7 bilhões) em relação ao ano anterior, tornando-se um valor bastante expressivo se comparado ao período analisado. Esse desempenho pode ser justificado por dois fatores, que, conforme Risco (2014), são a boa safra de soja, recorde, logo após o estado sofrer a estiagem que impactou negativamente nas exportações desta commodity em 2012 e o crescimento das exportações, via as plataformas de petróleo e gás para este período. Por fim, em 2013, estes fatores contribuíram para que o Rio Grande do Sul ficasse na terceira posição dos maiores estados exportadores, com 10,4\% do total exportado pelo Brasil. Os principais produtos gaúchos exportados, entre 2017 e 2018, são apresentados na Tabela 2.

Tabela 2 - Exportações Totais por Fator Agregado do ano de 2017 e 2018 em bilhões (US $\$$ FOB)

\begin{tabular}{lcc}
\hline \multirow{2}{*}{ Produtos } & $\mathbf{2 0 1 7}$ & $\mathbf{2 0 1 8}$ \\
\cline { 2 - 3 } Produtos Básicos & $\mathbf{9 . 2 8 3 . 0 6 9 . 4 5 7}$ & Valor FOB (US\$) \\
Produtos Manufaturados & 7.001 .300 .803 & $\mathbf{9 . 6 9 0 . 8 3 8 . 3 1 3}$ \\
Produtos Semimanufaturados & 1.373 .912 .121 & 9.594 .991 .898 \\
Operações Especiais & 123.976 .984 & 1.660 .237 .428 \\
Total das exportações & 17.782 .259 .365 & 92.861 .714 \\
\hline
\end{tabular}

Fonte: Elaborada pelos autores com base nos dados do MDIC (2019)

Nota-se que, entre os principais produtos gaúchos exportados, estão os produtos básicos e os manufaturados. Dentro da divisão por fator agregado, o valor das exportações aumentou em todos os segmentos, em comparação ao ano de 2017, com destaque para os produtos manufaturados, que aumentaram consideravelmente sua participação nas exportações totais, embora os produtos básicos ainda sejam os principais componentes da pauta exportadora.

Entre os produtos mais exportados pelo Rio Grande do Sul, durante o ano de 2018 (Tabela 3), destacam-se, especialmente, a soja, com receita de US $\$ 5,28$ bilhões e participação de $25 \%$ no valor total exportado pelo estado, seguido pelas plataformas de perfuração e exploração (produtos manufaturados), que corresponderam a um valor de US $\$ 2,83$ bilhões e participação de $13 \%$ e pelo fumo em folhas, que 
gerou uma receita de 1,47 bilhões e participação de $7 \%$ no total das exportações. Nota-se que a pauta exportadora é caracterizada pelo predomínio de produtos primários, principalmente a soja.

Tabela 3 - Principais produtos da pauta exportadora gaúcha no ano de 2018 (US\$ FOB)

\begin{tabular}{|c|c|c|c|c|}
\hline Produtos & Ranking & Fator Agregado & Valor FOB (US\$) & $\%$ \\
\hline Soja mesmo triturada & $1^{\circ}$ & Básicos & 5,28 Bilhões & $25,0 \%$ \\
\hline Plataformas de perfuraçãolexploração & $2^{0}$ & Manufaturados & & \\
\hline Fumo em folhas e desperdícios & $3^{\circ}$ & Básicos & Bilhões & $7,0 \%$ \\
\hline $\begin{array}{l}\text { Farelo e resíduos da extração de óleo de } \\
\text { soja }\end{array}$ & $4^{0}$ & Básicos & 975,31 Milhões & $4,6 \%$ \\
\hline $\begin{array}{l}\text { Polímeros de etileno, propileno e estireno. } \\
\text { Celulose }\end{array}$ & $\begin{array}{l}5^{\circ} \\
6^{0}\end{array}$ & $\begin{array}{l}\text { Manufaturados } \\
\text { Básicos }\end{array}$ & $\begin{array}{l}\text { 920,86 Milhões } \\
\text { 798,85 Milhões }\end{array}$ & $\begin{array}{l}4,4 \% \\
3,8 \%\end{array}$ \\
\hline $\begin{array}{l}\text { Carne de frango congelada, fresca ou } \\
\text { refrigerada, incl. Miúdos }\end{array}$ & $7^{\circ}$ & Básicos & 573,07 Milhões & $2,7 \%$ \\
\hline Automóveis de passageiros & $8^{\circ}$ & Manufaturados & 568,56 Milhõ & $2,7 \%$ \\
\hline Calçados & 90 & & 428,25 Milh & $2,0 \%$ \\
\hline Arroz em grãos, inclusive arroz quebrado & $10^{\circ}$ & Básicos & 426,96 Milhões & $2,0 \%$ \\
\hline
\end{tabular}

Fonte: Elaborada pelos autores, com base nos dados do MDIC (2019)

Os principais destinos das exportações gaúchas, no ano de 2018 (Tabela 4), foram a China (30\%), os Países Baixos (Holanda) (8,6\%), a Argentina (7\%), o Panamá $(7,0 \%)$ e os Estados Unidos $(6,4 \%)$, do total de seus produtos exportados. A China é a principal parceira comercial do Brasil e o principal destino das exportações do Rio Grande do Sul. As exportações gaúchas para a China vêm crescendo de forma sustentada e constante desde o início dos anos 2000, visto que, no ano de 2000, as exportações foram de US\$ 250 milhões, passando para US\$ 6.3 bilhões em 2018 (MDIC, 2019).

Tabela 4 - Principais destinos das exportações gaúchas no ano de 2018 em bilhões (US\$ FOB)

\begin{tabular}{lcc}
\hline Destino & Valor FOB (US\$) & Porcentagem \\
\hline China & 6.317 .940 .950 & $30,0 \%$ \\
Países Baixos (Holanda) & 1.804 .459 .550 & $8,6 \%$ \\
Argentina & 1.464 .598 .994 & $7,0 \%$ \\
Panamá & 1.348 .642 .631 & $6,4 \%$ \\
Estados Unidos & 1.316 .774 .226 & $6,3 \%$ \\
Chile & 489.959 .747 & $2,3 \%$ \\
Paraguai & 482.878 .053 & $2,3 \%$ \\
Bélgica & 471.731 .180 & $2,2 \%$ \\
Uruguai & 415.444 .848 & $2,0 \%$ \\
Coreia do Sul & 393.896 .653 & $1,9 \%$ \\
\hline
\end{tabular}

Fonte: Elaborada pelos autores, com base nos dados do MDIC (2019)

Os principais produtos gaúchos exportados para China são soja, celulose, fumo, carnes suínas, bovinas e de frango, ou seja, as exportações destinadas para este país são em grande parte produtos primários (MDIC, 2019). Entretanto, observa-se também a presença de produtos manufaturados e semimanufaturados, embora a maioria seja de baixo valor agregado. Destaca-se que, em 2017, das exportações totais para China, aproximadamente $86,3 \%$ correspondem a produtos básicos, $6,4 \%$ a produtos semimanufaturados e $7,1 \%$ a manufaturados (FEE, 2018).

\section{REVISÃO EMPÍRICA DE ESTUDOS}

Gomes e Fantinel (2012) avaliaram a influência da taxa de câmbio e da renda mundial sobre as exportações de calçados gaúchos para o período de 2003 a 2011. Para tal, utilizaram os métodos de séries temporais VAR e VECM. Os resultados apontaram que a taxa de câmbio real e a renda mundial são fatores determinantes na explicação da evolução do valor das exportações de calçados gaúchos, destacando que a variável renda mundial teve um impacto superior à variável taxa de câmbio sobre o valor das exportações calçadistas do Estado.

Paschoalino et al (2016) analisaram a relação entre câmbio e renda externa sobre a Balança Comercial de bens básicos no Paraná, para o período de 2000 a 2015. Os autores utilizaram as ferramentas de séries temporais, como o modelo VECM e elasticidades de transmissão de curto e longo prazo. Os resultados encontrados pelos autores sugerem que a balança comercial dos produtos básicos do Paraná é 
elástica, tanto em relação ao câmbio quanto à renda externa, indicando uma intensificação nas exportações de produtos básicos em decorrência das desvalorizações cambiais e o aumento da renda externa no período analisado.

Duarte e Hidalgo (2017) buscaram verificar a influência da renda mundial e da taxa de câmbio sobre as exportações da Bahia. Para tal, empregaram métodos de séries temporais, como o Modelo Vetorial Autorregressivo e o Modelo VECM. Os resultados encontrados pelos autores para a equação de longo prazo indicaram que a renda mundial afetou significantemente as exportações, enquanto a taxa de câmbio apresentou sinal negativo, apresentando relação inversa. Já a equação de curto prazo do vetor de cointegração apontou que, para a variável exportação, os desequilíbrios de curto prazo são corrigidos de forma relativamente rápida, o que não acontece para as variáveis taxa de câmbio e de renda mundial.

Sob a ótica das unidades federativas, Nascimento (2017) analisou, entre janeiro de 1999 a julho de 2013, a relação entre taxa de câmbio real efetiva e exportações líquidas através de modelos VAR e Mínimos Quadrados Ordinários Dinâmicos (MQOD). Como principais resultados alcançados, validaram a condição de Marshall-Lerner ao observar: i) a relação positiva das exportações líquidas com a depreciação cambial e a renda externa; ii) um coeficiente da renda doméstica negativo; iii) que a renda mundial e o câmbio são mais elásticos sobre a exportação líquida de básicos e menos sobre bens industrializados e iv) a ocorrência da curva $\mathrm{J}$, pois um choque no câmbio real causou um impacto negativo sobre a balança comercial, que se tornou superavitária apenas depois de quatro meses - exceto para os bens básicos.

Saccaro e Alvim (2017), tendo como foco a hipótese de desindustrialização para o Rio Grande do Sul, analisaram as mudanças que ocorreram na pauta de exportação gaúcha, de acordo com a intensidade tecnológica de seus produtos para os anos de 2007 a 2015, utilizando o Modelo Vetorial Autorregressivo (VAR). Além das variáveis taxa de câmbio e renda externalmundial, os autores acrescentam a variável taxa de juros. Os resultados encontrados evidenciaram que o aumento da participação de produtos primários na pauta de exportações gaúchas reduz de forma significativa as exportações de todas as categorias de bens manufaturados.

Monte (2015) estimou os efeitos da taxa de câmbio e renda mundial sobre as exportações do Espírito Santo, utilizando a metodologia VAR/VECM, e constatou que, em longo prazo, a renda mundial afeta significantemente as exportações do Espírito Santo, enquanto a taxa de câmbio apresentou sinal negativo e foi não significativa, sugerindo que a taxa de câmbio não possui significativos efeitos sobre as exportações. Além disso, nas funções impulso-resposta, verificou-se que um choque na taxa de câmbio tem efeitos negativos sobre as exportações em quase todos os períodos após o choque, contrariamente à teoria econômica, diferente da renda mundial, que continua afetando positivamente as exportações após um choque econômico.

Por fim, com base na análise dos estudos, foi possível compreender a importância e influência que a renda mundial tem sobre os fluxos comerciais regionais do Brasil. Entretanto, em relação à taxa de câmbio, há controvérsias, uma vez que se verificou que, para alguns estados e regiões do Brasil, a taxa de câmbio apresentou influência sobre os fluxos comerciais, porém, para outras, mostrou pouca ou nenhuma influência, uma vez que se caracterizou como não significativa. Todos os estudos supracitados utilizaram-se do uso de ferramentas de econométricas de séries temporais. Deste modo, na próxima seção, são discutidos os aspectos metodológicos que darão base para este estudo.

\section{METODOLOGIA}

O modelo econométrico utilizado no presente estudo fundamenta-se na metodologia dos modelos de Vetores Autorregressivos (VAR) e Vetor de Correção de Erros (VECM). O VAR proposto por Sims (1980) tem como objetivo determinar as inter-relações entre diversas variáveis endógenas. Cada variável endógena é explicada por seus valores defasados e pelos valores defasados de todas as demais variáveis endógenas no modelo (BUENO, 2008).

De forma analítica, o VAR(p) é definido por:

$$
Y_{t}=\Phi i Y_{t}-1+\Phi 2 Y_{t}-2+\cdots+\Phi p Y_{t}-p+\varepsilon_{t}
$$

em que: Yt é um vetor de variáveis composto por: logaritmo natural das exportações gaúchas de produtos básicos $\left(\ln \operatorname{Exp}_{t}\right)$; logaritmo natural do valor da taxa de câmbio real efetiva (lnCambio $\left.{ }_{t}\right)$; logaritmo natural da

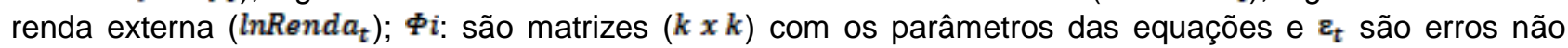
correlacionados, com média zero e variância constante.

Para a estimação desse modelo, é necessário que as variáveis sejam estacionárias, pois, caso elas não sejam, de acordo com Enders (2010), as variáveis precisam ser diferenciadas antes da estimação do modelo. Entretanto, a diferenciação das variáveis causa omissão de existência de relações de longo prazo, por isso, é necessário, no caso de variáveis não estacionárias, verificar a ordem de integração, e, se as 
variáveis forem integradas de mesma ordem, realiza-se o teste de cointegração. $\mathrm{Na}$ presença de cointegração, deve-se estimar o VECM.

Para uma série temporal ser considerada estacionária, ou fracamente estacionária, sua média e variância devem permanecer constantes ao longo do tempo. Para verificar se a série é estacionária em nível ou estacionária em primeira diferença, optou-se pelo uso dos respectivos testes: Dickey-Fuller Aumentado (ADF) e Phillips-Perron (PP), ambos com hipótese nula com a presença de raiz unitária, e como hipótese alternativa, a ausência de raiz unitária. Esses testes desconsideram as possíveis quebras estruturais, podendo apresentar resultados imprecisos.

Se a quebra estrutural ocorrer, o teste DFA e PP tornam-se viesados, apresentando uma falsa rejeição da hipótese nula de raiz unitária, uma vez que é possível que tenha raiz unitária com quebra estrutural (PIAS, 2017). Assim, sugere-se realizar também o teste Kwiatkowski-Phillips-Schmidt-Shin (KPSS), que tem como hipótese nula ausência de raiz unitária e, como hipótese alternativa, a presença de raiz unitária para dar maior precisão nos resultados. Contudo, se houver desconfiança de uma possível quebra estrutural na série, dado que, em geral, as séries econômicas são afetadas por choques ou eventos exógenos, como alteração de política macroeconômica, variações climáticas, entre outros, torna-se necessário realizar teste de estacionaridade Harvey-Collier para quebra estrutural Múltipla, sob a hipótese nula, em que a soma acumulada dos residuais terá média zero, ou seja, não há quebra estrutural significativa no processo em questão.

Então, se a hipótese nula é rejeitada, há quebras estruturais na série em questão. Assim, os próximos procedimentos serão realizar teste de raiz unitária com quebra estrutural, que permite testar a existência de raiz unitária em séries com quebras estruturais, incorporando diferentes formas de quebras estruturais: i) Outlier Aditivo (OA), que captura mudanças abruptas e ii) Outlier Inovacional (OI) que captura mudanças graduais na série (FIORENTIN, 2018).

$\mathrm{Na}$ sequência, para obter maior robustez nos resultados, será feito o teste de cointegração. Incialmente, utilizou-se o teste de cointegração de Johansen (1988), verificando se existe uma relação estável de longo prazo entre as séries temporais e com o intuito de prevenir regressões espúrias. A cointegração significa que, mesmo que as séries sejam individualmente não estacionárias, a combinação linear de duas ou mais séries pode ser estacionária (BUENO, 2008). Se houver cointegração, o próximo procedimento clássico é estimar o VECM.

O VECM possui a seguinte especificação:

$$
\Delta Y_{t}=\phi Y_{t-1}+\sum_{i=0}^{p-1}{ }_{\Delta_{i}} \Delta Y_{t-i}+e_{t}
$$

Considerando que exista cointegração, o VECM decompõe $\Delta Y_{t}$ em dois componentes: os fatores de curto prazo, $\sum_{i=0}^{p-1} \Delta_{i} \Delta Y_{t-i}$, e relação de longo prazo dada entre as coordenadas do vetor de variáveis endógenas, $\phi Y_{t-1}$ (BUENO, 2008). Bueno (2008) ressalta que o modelo VECM possui significado econômico, pois, em virtude da dinâmica comum, as variáveis têm um componente de longo prazo e um de curto prazo.

Destaca-se que a seleção de defasagem é determinada pelos métodos tradicionais de Akaike (AIC), Schwarz (SBC) e Hannan-Quinn (HQ).

\subsection{Fonte de dados}

O trabalho utilizou dados das exportações de produtos básicos do Estado do Rio Grande do Sul, do período de janeiro de 2001 a outubro de 2018, fornecidos pelo MDIC, deflacionados pelo IPA-Índice de Preços ao Produtor Amplo dos Estados Unidos em índice com média 2010, divulgado pelo Internacional Financial Statistics do Fundo Monetário Internacional (FMI/IFS).

Como proxy da renda externa, utilizou-se o valor das importações mundiais, assim como nos estudos de Duarte e Hidalgo (2017) e Monte (2015), onde os dados são fornecidos pelo Internacional Financial Statistics do Fundo Monetário Internacional (FMI/IFS), deflacionados pelo IPA dos Estados Unidos em índice com média 2010. Os dados da taxa de câmbio real efetiva foram obtidos no IPEADATA, em índice com base 2010.

\section{ANÁLISE E DISCUSSÃO DOS RESULTADOS}

Os resultados a respeito dos efeitos da taxa de câmbio real e da renda externa no saldo da balança comercial de produtos básicos do Rio Grande do Sul foram alcançados por meio de um conjunto de procedimentos econométricos, conforme detalhado na seção anterior. 
Inicialmente, analisou-se a evolução de cada série de dados das variáveis utilizadas (Figura 1) ao longo do período de 2001 a 2018. Destaca-se que as variáveis InExp e InRenda apresentaram um comportamento e uma tendência semelhante ao longo do período, sendo que, no biênio de 2008/2009, tiveram uma forte queda devido à crise internacional de 2008 (subprime). Já no ano de 2013, maior pico das exportações do Rio Grande do Sul, observa-se um aumento nas importações mundiais (renda externa), afetando as exportações gaúchas.

Figura 1 - Evolução das séries ao longo do período de janeiro de 2001 a outubro de 2018

(a) 1.600 .000 .000
1.400 .000 .000
1.200 .000 .000
1.000 .000 .000
800.000 .000
600.000 .000
400.000 .000
200.000 .000 Exportações dos Produtos Básicos do RS $(\ln E X P)$

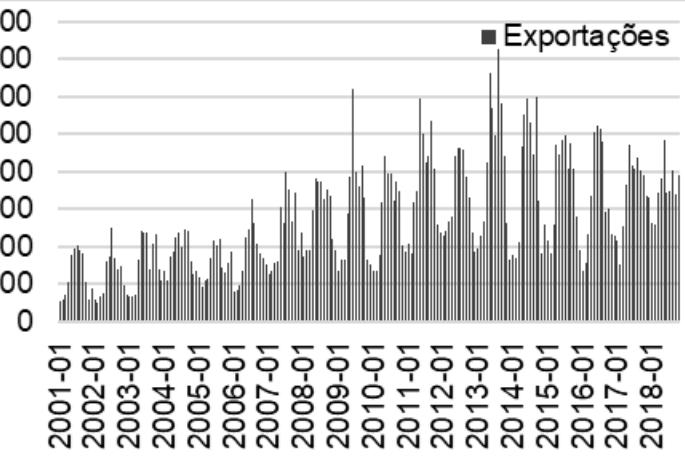

(b) Taxa de Câmbio Real Efetiva (lnCambio)

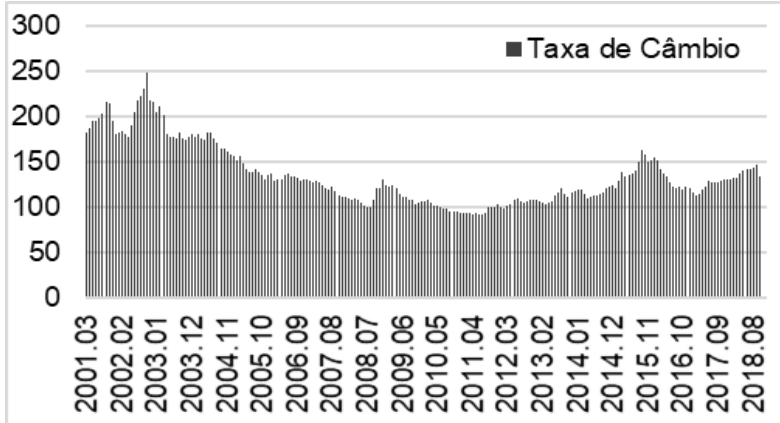

c) Renda Externa (lnRenda)

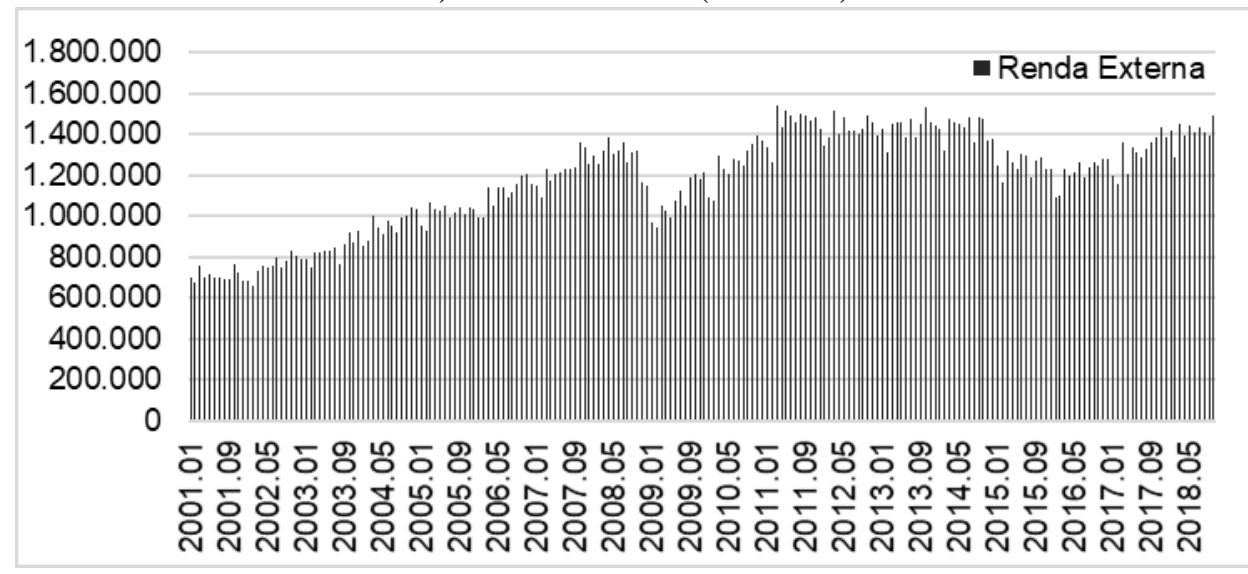

Fonte: Elaborado pelos autores

Foi possível verificar que, entre 2001 e 2002, a variável InCâmbio estava desvalorizada. Após este período, voltou a se valorizar ao longo dos anos, atingindo um de seus maiores picos em 2008. Destaca-se que, mesmo com essa valorização, no período, as exportações do Brasil, em especial os produtos básicos, continuaram em crescimento (ZIANI, 2018). Esse aumento das exportações do Rio Grande do Sul é justificado pelo boom dos preços das commodities, que iniciou em 2002, impulsionando as exportações de produtos básicos brasileiros, tanto em termos de quantidade quanto de valor, mesmo com a taxa de câmbio efetiva real se apreciando. Ainda nesta perspectiva, observa -se que a taxa de câmbio brasileira apresentou uma desvalorização cambial a partir do biênio de 2015/2016, obtendo seu mínimo em janeiro de 2016.

Dando continuidade aos procedimentos econométricos, a primeira etapa para analisar as séries temporais em um modelo VAR é verificar como o processo estocástico gerador das séries temporais se comporta ao longo do tempo, ou seja, identificar se as variáveis são ou não estacionárias.

Os testes de raiz unitária utilizados para verificar a estacionariedade das séries foram o teste DickeyFuller Aumentado (ADF), o teste Phillips-Perron e o teste Kwiatkowski-Phillips-Schmidt-Shin (KPSS). Em ambos os testes, o número de defasagens utilizadas foi determinado pelo critério de Schwarz (BIC). Os resultados são apresentados na Tabela 5. 
Tabela 5 - Resultado dos testes de raiz unitária ADF, PP e KPSS

\begin{tabular}{|c|c|c|c|c|c|c|}
\hline Variáveis & \multicolumn{2}{|c|}{$\begin{array}{c}\text { Estatística de } \\
\text { teste ADF }\end{array}$} & \multicolumn{2}{|c|}{$\begin{array}{c}\text { Estatística de } \\
\text { teste PP }\end{array}$} & \multicolumn{2}{|c|}{$\begin{array}{c}\text { Estatística de } \\
\text { teste KPSS }\end{array}$} \\
\hline \multicolumn{7}{|c|}{ Séries em nível } \\
\hline $\ln \operatorname{Exp}$ & -2.787 & *** & -4.791 & *** & $\mathrm{p}<.01$ & *** \\
\hline InCâmbio & -1.707 & ** & -1.544 & * & $p<.01$ & *** \\
\hline InRenda & -1.954 & ** & -2.048 & ** & $\mathrm{p}<.01$ & *** \\
\hline \multicolumn{7}{|c|}{ Séries em primeira diferença } \\
\hline$\Delta \ln E x p$ & -12.404 & *** & - & - & $p>.10$ & *** \\
\hline$\Delta$ InCâmbio & -9.184 & *** & -11.076 & *** & $p>.10$ & *** \\
\hline$\Delta \operatorname{lnRenda}$ & -10.014 & *** & -22.837 & *** & $p>.10$ & *** \\
\hline
\end{tabular}

Fonte: Elaboração própria com base nos dados da pesquisa

Nota ${ }^{1}$ *** significativo a $1 \% ;{ }^{* *}$ significativo a $5 \%$; ${ }^{*}$ significativo a $10 \%$; ns não significativo

O valor crítico calculado do teste ADF é, em módulo, menor do que os valores críticos tabelados a $10 \%, 5 \%$ e $1 \%$ de significância

Os testes de ADF e Phillips-Perron para as séries em nível de InCâmbio e InRenda indicaram a não rejeição da hipótese nula de que elas apresentam raiz unitária, em nível de $1 \%, 5 \%$ e $10 \%$ de confiança, o que permite inferir que essas séries são não estacionárias, contudo, após uma diferença, tornam-se estacionárias em ordem I(1). Para a análise da série InExp, o teste de Phillips-Perron apresentou a rejeição da hipótese nula, logo a série não apresenta raiz unitária, sendo estacionária em nível, ordem I(O). Contudo, pelo teste de ADF, a série InExp é não estacionária, contudo, após uma diferença, torna-se estacionária em ordem I(1). Já com os resultados evidenciados com o teste KPSS, rejeita-se a hipótese nula, em nível, ou seja, todas as séries apresentam raiz unitária e não são estacionárias, entretanto, após uma diferença, tornam-se estacionárias em ordem I(1).

Assim, como os resultados foram contraditórios entre os testes de estacionaridade, realizou-se o teste de quebra estrutural múltipla para verificar se os coeficientes são estáveis ao longo do tempo, pois a presença de quebra estrutural leva a um viés na aplicação dos testes de raiz unitária e de cointegração (MADDALA; KIM, 1998).

Desta forma, adotando este argumento, aplicou-se o teste $t$ de Harvey-Collier com o intuito de identificar possíveis quebras estruturais, apresentado na Tabela 6.

Tabela 6 - Resultados do teste de quebra estrutural múltipla para as séries analisadas

\begin{tabular}{cc}
\hline Séries & Estatística do teste \\
\hline InExp & 0.8121 \\
InCâmbio & $\mathbf{1 . 4 3 2 0}$ \\
InRenda & 0.8083 \\
\hline
\end{tabular}

Fonte: Elaboração própria com base nos dados da pesquisa

Nota $^{1}$ : o teste de quebra estrutural Harvey-Collier tem como hipótese nula a ausência (não presença) de quebra estrutural, enquanto a hipótese alternativa aponta a presença de quebra estrutural. Os valores críticos para o teste são: $1 \%$ de significância $1,1430,5 \%$ de significância 0,9479 e $10 \%$ de significância $0,850 .{ }^{*},{ }^{* *} e^{* * *}$ indicam a rejeição da hipótese nula a $1 \%, 5 \%$ e $10 \%$, respectivamente.

Verificou-se que as séries InExp e InRenda não apresentaram quebras estruturais, ao contrário do que ocorreu com a InCâmbio. Assim, o próximo passo é realizar o teste de raiz unitária com quebras estruturais, pois, como as séries passaram por diversas mudanças institucionais, em especial a taxa de câmbio é mais sensível aos choques econômicos. Assim, realizou-se o teste de raiz unitária com quebra estrutural (Tabela 7), que permite testar a existência de raiz unitária em séries com quebras estruturais, como o caso da InCâmbio.

Tabela 7 - Teste de raiz unitária com quebra estrutural para Taxa de Câmbio (InCâmbio)

\begin{tabular}{c|cccc}
\hline & Tipo & Quebra & Valor crítico t & Estatística t \\
\hline InCâmbio - em nível & 10 & Outubrol2011 & -4.894 & 74.026 \\
\hline $\begin{array}{c}\Delta \text { InCâmbio - em primeira } \\
\text { diferença }\end{array}$ & 10 & Outubrol2011 & -12.446 & $2.285^{\star * *}$ \\
\hline
\end{tabular}

Fonte: Elaboração própria com base nos dados da pesquisa

Nota ${ }^{1}$ : ** significativo a $1 \%$; ${ }^{* *}$ significativo a $5 \%$; ${ }^{*}$ significativo a $10 \%$; ns não significativo.

Identificou-se a quebra estrutural de Outlier Inovacional (OI), que captura mudanças graduais na série InCâmbio para o período de outubrol2001. Da mesma forma que nos testes anteriores (KPSS, PP e DFA), a InCâmbio tornou-se estacionária em primeira diferença, não apresentando raiz unitária. Essa quebra estrutural pode ser explicada pela desvalorização do real causada pela crise argentina e, também, pela 
recessão americana, quando, a partir do primeiro trimestre de 2001, o preço do dólar disparou no Brasil (NEPOM, 2014).

Como os pré-requisitos de testes foram satisfeitos, em que as séries são de ordem I(1) (BUENO, 2008), realizou-se o teste de cointegração entre todas as séries para verificar relação estável de longo prazo entre as séries temporais.

Mas, antes disso, é preciso definir o número de defasagem ótimo. Para tanto, utilizaram-se duas defasagens, conforme Tabela 8, seguindo o critério de informação de Schwarz (SBIC), por ser considerado mais robusto e parcimonioso (STOCK, 1994).

Tabela 8 - Diferentes critérios para seleção de defasagens

\begin{tabular}{ccccccc}
\hline Defasagem & LogL & LR & FPE & AIC & SC & HQ \\
\hline 0 & 52.9016 & - & 0.000125 & -0.475253 & -0.455923 & -0.427438 \\
1 & 700.888 & 1296 & $2.8 \mathrm{e}-07$ & -6.56084 & -6.48352 & -6.36957 \\
$\mathbf{2}$ & 733.972 & 66.168 & $2.3 \mathrm{e}-07$ & -6.79021 & -6.65489 & $\mathbf{- 6 . 4 5 5 5 ^ { \star }}$ \\
3 & 755.32 & 42.696 & $2.0 \mathrm{e}-07$ & -6.90781 & $\mathbf{- 6 . 7 1 4 5}$ & -6.42965 \\
4 & 766.612 & $\mathbf{2 2 . 5 8 5}^{\star}$ & $\mathbf{2 . 0 e - 0 7 ^ { \star }}$ & $\mathbf{- 6 . 9 2 9 6 4 ^ { \star }}$ & -6.67835 & -6.30803 \\
\hline
\end{tabular}

Fonte: Elaboração própria com base nos dados da pesquisa

Nota $^{1}$ : valor da verossimilhança (LogL); $p$-valor do teste de razão de verossimilhança (LR); Erro de Predição Final (FPE); Critério de Informação de Akaike (AIC); Critério de Informação Bayesiano de Schwarz (BIC); e o Critério de Informação de Hannan \& Quinn (HQC) . Nota 2: *indica a defasagem ótima (n) definida pelo critério.

Definidas as defasagens, realizou-se o teste de cointegração de Johansen, do traço e de máximo autovalor. Os testes de traço e de máximo autovalor (Tabela 9) revelam a presença de apenas um vetor de cointegração, sendo a estatística traço significativa a $1 \%$.

Tabela 9 - Teste de cointegração de Johansen

\begin{tabular}{ccccc}
\hline & \multicolumn{2}{c}{ Estatística do Traço } & \multicolumn{2}{c}{ Estatística do Máximo Autovalor } \\
\hline & Calculado & Autovalor & Calculado & Autovalor \\
\hline $\mathrm{R}=0$ & 64.9274 & - & 48.8874 & - \\
$\mathbf{R} \leq 1$ & $\mathbf{1 6 . 0 4 0 0 ^ { * } \mathbf { 1 } ( { } ^ { \star \star \star } )}$ & 0.20594 & 13.1100 & 0.20594 \\
$\mathrm{R} \leq 2$ & $2.9300^{\star} 5$ & 0.05997 & 2.9300 & 0.05997 \\
$\mathrm{R} \leq 3$ & - & 0.01373 & - & 0.01373 \\
\hline
\end{tabular}

Fonte: Elaboração própria com base nos dados da pesquisa

Nota ${ }^{1}$ : ${ }^{* \star \star}$ significativo a $1 \% ;{ }^{* \star}$ significativo a $5 \% ;{ }^{*}$ significativo a $10 \%$; ns não significativo.

Buscando determinar a ordem de entrada das variáveis no modelo, foi realizado o teste de causalidade de Granger (1969). A causalidade de Granger refere-se aos efeitos que os valores passados de uma variável causam no valor atual de outra variável. Portanto, a causalidade de Granger mede se os valores atuais e passados de uma variável ajudam a prever ou influenciar nos valores futuros de uma outra variável (ENDERS, 2010). Neste método, as variáveis devem ser estacionarias, assim, empregou-se o procedimento neste estudo com as séries diferenciadas.

Tabela 10 - Teste de causalidade de Granger

\begin{tabular}{|c|c|c|}
\hline Hipótese Nula & Estatística F & $p$-valor \\
\hline$\Delta$ InCâmbio não causa $\Delta \operatorname{lnExp}$ & 3.0978 & 0.212 \\
\hline$\Delta \operatorname{lnRenda}$ não causa $\Delta \ln E x p$ & 0.7563 & 0.685 \\
\hline$\Delta \operatorname{lnExp}$ não causa $\Delta$ lnCâmbio & 2.8143 & 0.245 \\
\hline$\Delta \operatorname{lnRenda~não~causa~} \Delta$ lnCâmbio & 7.3503 & 0.025 \\
\hline$\Delta \ln E x p$ não causa $\Delta \ln R e n d a$ & 4.1766 & 0.124 \\
\hline$\Delta \operatorname{lnCâmbio~não~causa~} \Delta \ln R e n d a$ & 3.5741 & 0.167 \\
\hline
\end{tabular}

Fonte: Elaboração própria com base nos dados da pesquisa

Os resultados do teste de Granger indicam que, a $5 \%$ de significância estatística, somente a renda Granger-causa o câmbio e a 1\% de significância estatística nenhuma variável Granger-causa outra variável. Dessa forma, a partir da teoria econômica, pressupõe-se que a série exportações é a mais endógena. Ainda, as interações entre as três variáveis são verificadas com a decomposição da variância dos erros de previsão (Tabela 12). 
Após a realização desses testes, estimou-se o VECM, cujos resultados são apresentados na Tabela 11 e fornecem informações importantes sobre a sensibilidade das exportações de produtos básicos do Rio Grande do Sul, em relação às variações na taxa de câmbio e na renda externa. É importante destacar que os sinais dos coeficientes do vetor de longo prazo devem ser analisados de maneira inversa.

Tabela 11 - Estimativas dos coeficientes de curto e longo prazo do Modelo Vetorial de Correção de Erros

\begin{tabular}{lccc}
\multicolumn{3}{c}{$(\mathrm{VECM})$} \\
Séries & $\begin{array}{c}\text { Estimativas dos coeficientes de } \\
\text { ajuste de curto prazo }(\alpha)\end{array}$ & $\begin{array}{c}\text { Estimativas dos coeficientes de } \\
\text { Longo Prazo }(\beta)\end{array}$ & p-valor \\
\hline LnExp & -0.3140 & 1.0000 & - \\
InCâmbio & $\mathbf{0 . 0 1 0 1}$ & $-\mathbf{0 . 2 9 1 6 8}$ & $\mathbf{0 . 4 9 0}$ \\
InRenda & 0.0101 & -1.99281 & 0.000 \\
Constante & - & 9.24012 & - \\
\hline
\end{tabular}

Fonte: Elaborado pelos autores a partir dos dados da pesquisa

Inicialmente, ao analisar os coeficientes de longo prazo $(\beta)$ do VECM, pode-se destacar que o valor de 1,99 para o coeficiente das importações mundiais, utilizadas como proxy para a Renda Externa neste estudo (InRenda), indica que a variável exportações gaúchas de produtos básicos (InExp) é sensível a variações na renda externa, e tal coeficiente sinaliza uma relação elástica na transmissão renda externaexportações. Dada uma variação de $1 \%$ na renda externa, aproximadamente 1,99\% dessa variação é transmitida às exportações de produtos básicos do Rio Grande do Sul. Destaca-se que o crescimento das economias do exterior estimula suas demandas por importações e, em consequência, os produtos brasileiros são procurados por importadores de diversos países (ZIANI, 2018), em especial, as commodities do Rio Grande do Sul, que é o quarto maior estado brasileiro exportador.

Esse fator reflete-se na variável taxa de câmbio (InCâmbio), visto que não se observou uma relação estatisticamente significativa para explicar as exportações de produtos básicos do Rio Grande do Sul (RS), indicando que a taxa de câmbio real não apresenta influência sobre as exportações de produtos básicos gaúchos, dado que, independentemente da sua valorização (desvalorização), as exportações continuam apresentando aumento na demanda. Esse resultado é corroborado com Monte (2005), o qual evidenciou que, no longo prazo, a renda mundial afeta significantemente as exportações, enquanto a taxa de câmbio apresentou sinal negativo e foi não significativa, sugerindo que a taxa de câmbio não possui significativos efeitos sobre as exportações do estado.

O fato de a elasticidade da renda externa ser muito superior à elasticidade da taxa de câmbio permite inferir que as exportações gaúchas de produtos básicos respondem melhor a uma variação na renda externa do que na taxa de câmbio. $O$ crescimento da renda mundial e, consequentemente, o aumento da demanda fazem com que as exportações não sejam tão dependentes da taxa de câmbio. Como já destacado, pode-se inferir que, mesmo com a valorização da taxa de câmbio, as exportações gaúchas de produtos básicos continuam em constante crescimento, sustentado especialmente pelo crescimento da China, principal parceira comercial do Brasil e principal destino das exportações de produtos básicos gaúchos, como já ressaltado.

Quanto à análise dos coeficientes de ajuste de curto prazo $(\alpha)$ do VECM, este mostra a velocidade do ajustamento das séries utilizadas no modelo de curto prazo. O coeficiente estimado InExp foi de aproximadamente $(-0,3140)$, indicando que os desequilíbrios de curto prazo das exportações tendem a ser corrigidos $31,40 \%$ em cada período, ou seja, em um tempo relativamente curto, atinge-se o equilíbrio de longo prazo. No caso do InCâmbio e InRenda, os desequilíbrios de ajuste no curto prazo tendem a serem corrigidos lentamente, com a velocidade de $1,01 \%$ em cada período em direção ao equilíbrio de longo prazo. Esses resultados podem ser justificados pelo fato de que as exportações de produtos básicos gaúchos é muito dependente de variações na renda externa, enquanto as exportações gaúchas têm pouca influência no comércio internacional. Assim, conclui-se que, no longo prazo, o desequilíbrio de preços nas exportações de produtos básicos gaúchas é reduzido muito mais rapidamente em comparação àquele obtido para a renda externa e para a taxa de câmbio.

Por fim, para complementar as análises e demonstrar a influência das variáveis taxa de câmbio e da renda externa sobre as exportações de produtos básicos do Rio Grande do Sul, apresentam-se as funções impulso-resposta, calculadas a partir do modelo VECM. Com a funções de impulso-resposta, analisa-se a trajetória da variável exportações de produtos básicos (InExp) frente a choques não antecipados - de magnitude de um desvio-padrão - nas variáveis taxa de câmbio efetiva (InCâmbio) e renda externa (InRenda) (Figura 2). 
Figura 2 - Trajetória das funções de impulso-resposta da variável das exportações de produtos básicos (InExp) frente a choques não antecipados nas variáveis taxa de câmbio efetiva (InCâmbio) e renda externa (InRenda) - 8 períodos à frente

a) Trajetória das funções de impulso-resposta da variável das exportações de produtos básicos (InExp) frente a choques não antecipados nas variáveis renda externa (InRenda)

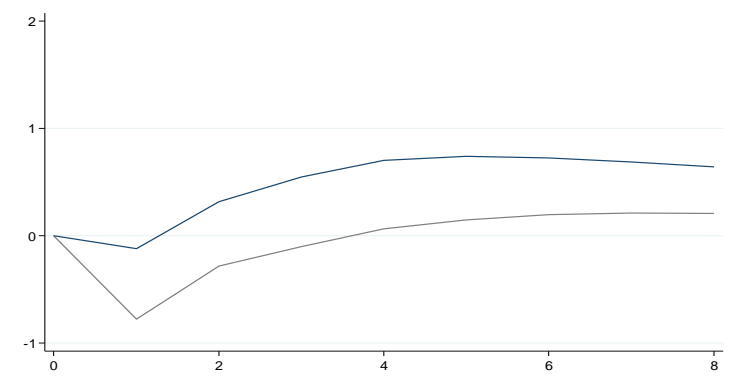

b) Trajetória das funções de impulso-resposta da variável das exportações de produtos básicos (InExp) frente a choques não antecipados nas variáveis taxa de câmbio efetiva (InCâmbio)

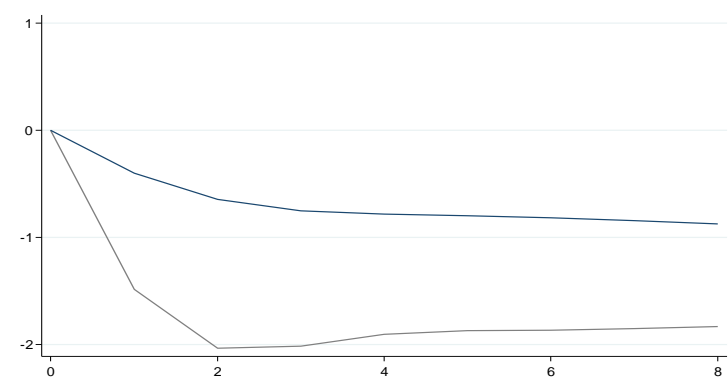

c) Trajetória das funções de impulso-resposta da variável das exportações de produtos básicos (InExp) frente a choques não antecipados nas variáveis das exportações de produtos básicos (InExp)

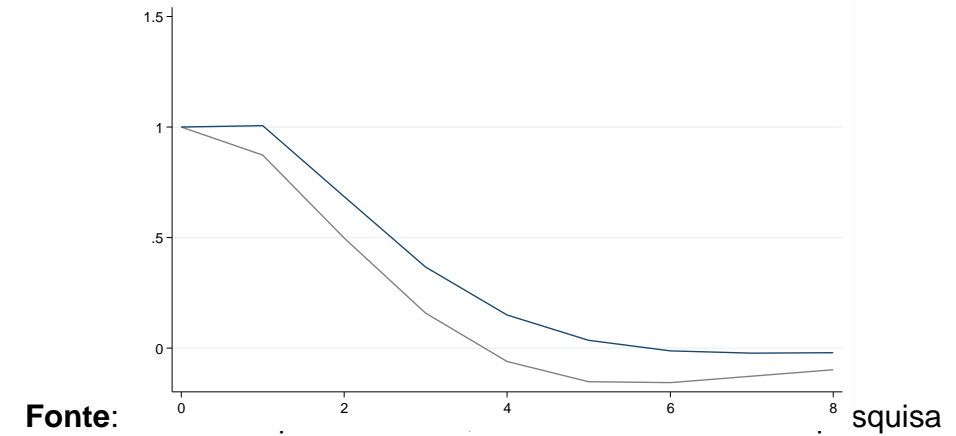

Destaca-se, também, que a trajetória das exportações gaúchas de bens básicos frente a um choque de um desvio-padrão não antecipado na taxa de câmbio causa um efeito negativo sobre as exportações, praticamente, em quase todos os períodos (8 meses). Os resultados encontrados no presente estudo corroboram com os estudos de Monte (2015) e Duarte e Hidalgo (2017), visto que a taxa de câmbio não se mostrou importante para as exportações no que se refere ao crescimento, frente a uma elevação de um desvio-padrão, causando resultados negativos, contrário ao esperado pela teoria econômica.

Já a trajetória da balança comercial gaúcha de bens básicos, frente a um choque não antecipado, em termos de desvio-padrão na renda externa, leva a sucessivos aumentos nas exportações de produtos básicos gaúchos, que se perpetuam por oito períodos. Então, ao chegar ao final do período, as exportações ficam bem acima do patamar inicial, ou seja, antes do choque na InRenda. Isso evidencia que o crescimento da demanda mundial impacta diretamente nas exportações do Rio Grande do Sul.

Ao analisar a trajetória das exportações gaúchas de bens básicos frente a um choque não antecipado sobre a própria balança comercial gaúcha de bens básicos, identifica-se que esta variável tem efeitos sobre seus próprios valores futuros até o quinto período.

Pode-se verificar que a renda externa tem uma grande influência sobre as exportações gaúchas, como já observado na evolução das variáveis InExp e InRenda, ilustrado na Figura 1, as quais apresentaram comportamento e tendência semelhante ao longo do período de 2001 a 2018. O VAR 
permitiu ainda um complemento para a análise das funções de impulso-resposta, uma realização do exercício de decomposição da variância do erro de previsão (Tabela 12) para averiguar o poder explicativo de cada variável do modelo sobre as demais.

Tabela 12 - Decomposição da variância dos erros de previsão das exportações de produtos básicos do RS (InExp)

\begin{tabular}{cccc}
\hline Período & InExp & InCâmbio & InRenda \\
\hline 1 & 1 & 0 & 0 \\
2 & 0.998644 & 0.001092 & 0.000263 \\
3 & 0.994831 & 0.003483 & 0.001686 \\
4 & 0.98765 & 0.006665 & 0.005685 \\
5 & 0.977631 & 0.010234 & 0.012134 \\
6 & 0.966896 & 0.013935 & 0.019169 \\
7 & 0.956464 & 0.017727 & 0.025809 \\
8 & 0.946751 & 0.021656 & 0.031592 \\
\hline
\end{tabular}

Fonte: Elaborado pelos autores, com base em dados da pesquisa

Assim, identifica-se que cerca de $94,6 \%$ da variância dos erros de previsão da variável InExp é explicada pela própria InExp. Quanto a InCâmbio e InRenda, explicam, respectivamente, aproximadamente cerca de $2,2 \%$ e $3,2 \%$ da variância do erro de previsão ao final de oito meses, ou seja, o poder de explicação da renda mundial vai se tornando relativamente superior ao da taxa de câmbio, revelando, do mesmo modo, a importância do cenário internacional para as exportações de produtos básicos do Rio Grande do Sul.

\section{CONCLUSÕES}

Como apontado pelo estudo, pode-se concluir que as exportações de produtos básicos são importantes para a economia gaúcha e para a obtenção de superávits na balança comercial. Em função disto, o objetivo do trabalho foi o de analisar a influência da taxa de câmbio e da renda externa sobre as exportações destes produtos.

$\mathrm{Na}$ análise de cointegração, os resultados indicaram que as exportações gaúchas de produtos básicos, a taxa de câmbio e a renda externa possuem um relacionamento de longo prazo, apresentando dois vetores de cointegração a $5 \%$ de significância estatística. No longo prazo, pode-se concluir que as exportações de produtos básicos são elásticas em relação à renda externa. A variável taxa de câmbio não teve significância estatística.

As estimativas de curto prazo demonstram que, para a variável exportações de produtos básicos gaúchas (InExp), os desequilíbrios de curto prazo se ajustam de forma relativamente rápida, mas, para a variáveis taxa de câmbio (InCâmbio) e importações mundiais, utilizada como proxy da renda externa, (InRenda) os desequilíbrios de curto prazo se ajustam lentamente.

A renda externa exerce uma grande influência sobre as exportações de bens básicos, o que pode indicar que o crescimento mundial, sustentado especialmente pelo crescimento da China, principal parceira comercial do Brasil e principal destino das exportações de produtos básicos gaúchos, o que corrobora a importância do cenário internacional para as exportações de produtos básicos gaúchos.

Dada a importância que os produtos básicos exercem sobre a balança comercial do Rio Grande do Sul, analisar os fatores que influenciam as exportações destes bens primários é fundamental para que os gestores públicos e empresários do ramo possam tomar decisões com mais acuidade e assim melhorar 0 desempenho exportador e gerar ainda mais divisas para o estado.

Como limitação, destaca-se que as variáveis utilizadas não são os únicos fatores que interferem nas exportações, por isso, para os próximos estudos, sugere-se incluir mais variáveis no modelo para que a análise seja feita com mais acuidade. Além disso, pode-se expandir a pesquisa para as demais indústrias de intensidade tecnológica, ou seja, para os semimanufaturados e manufaturados.

\section{REFERÊNCIAS}

ATLAS SÓCIO ECONÔMICO DO RIO GRANDE DO SUL. Dados. Disponível em: <https://atlassocioeconomico.rs.gov.br/inicial>. Acesso em 22 de abril de 2019

BRAGA, F. L. P.; OLIVEIRA, A. C. S. A Influência da Taxa de Câmbio e Renda Mundial Sobre as Exportações Brasileiras de Soja (2000-2015). Revista de Economia e Sociologia Rural. Brasília. v. 56 n.4. out./dez. 2018

BUENO, R. L. S. Econometria de séries temporais. São Paulo: Cengage Learning, 2008. 
CALDAS, B. B. O desempenho das exportações gaúchas em 2012. Indic. Econ. FEE, Porto Alegre, v. 40, n. 4, p. 5160, 2013.

CARNEIRO, F. L. A influência da taxa de câmbio sobre os fluxos de comércio exterior. Texto para discussão, n.1967, 58p, 2014.

COMEXSTAT. Exportação e Importação Geral. Disponível em: <http://comexstat.mdic.gov.br/pt/geral>. Acesso em: 17 de abr. 2019.

DUARTE, L. B.; HIDALGO, A. B. O efeito da taxa de câmbio e da renda mundial sobre as exportações do estado da Bahia no período de 2001 a 2016. Reflexões Econômicas, Ilhéus (BA). n.3. v.1. p. 1-20. out. 2016/mar. 2017.

ENDERS, W. Applied econometric time series. 3. ed. New York: John Wiley and Sons, 2010.

FIORENTIN, G. P. A dinâmica do repasse cambial para a inflação no brasil durante o período de 2001 a 2017. 2018. Disponível em: https://www.lume.ufrgs.br/bitstream/handle/10183/190101/001090837.pdf?sequence=1. Acesso em: 26 de dez. 2019.

FUNDAÇÃO DE ECONOMIA E ESTATÍSTICA SIEGFRIED EMANUEL HEUSER. Dados. Porto Alegre, 2018. Disponível em: <https://www.fee.rs.gov.br/indicadores/indice-das-exportacoes/destaque-do-mes/>. Acesso em: $10 \mathrm{de}$ jun. 2019.

FUNDO MONETÁRIO INTERNACIONAL - FMI. 2019. IMF data. Disponível em: <https://www.imf.org/en/Data>. Acesso em: 18 abril. 2019.

GOMES, E. C.; FANTINEL, V D. O impacto da taxa de câmbio e da renda mundial nas exportações de calçados gaúchos. In: 6 Encontro de Economia Gaúcha. 2012. Porto Alegre. Anais... Porto Alegre: FEE, 2012.

GRANGER, C. W. J. Investigating causal relations by econometric models and cross-spectral methods. Econometrica, v. 37, n. 3, 1969.

GREENE, W. H. Econometrics Analysis. 6.ed. New Jersey: Pearson Education, 2008.

INSTITUTO DE PESQUISA ECONÔMICA APLICADA (IPEA). Ipeadata. 2019. Disponível em: <www.ipeadata.gov.br>. Acesso em: 15 de abr. 2019.

JOHANSEN, S. Statistical analysis of cointegration vectors. Journal of Economic Dynamics and Control, v.12, p.231254, 1988.

MADDALA, G. S.; KIM, I-M. (1998). Unit Roots, Cointegration, and Structural Change. Cambridge: Cambridge University Press.

MDIC - Ministério do Desenvolvimento, Indústria e Comércio Exterior. Exportação e Importação. 2019. Disponível em: <http://www.mdic.gov.br/>. Acesso em: 15 de abr. 2019.

MONTE, E. Z. Influência da taxa de câmbio e da renda mundial nas exportações do Estado do Espírito Santo. Análise Econômica, Porto Alegre, ano 33, n. 63, p. 301-323, mar. 2015.

NASCIMENTO, G. M. do. Taxa de câmbio e exportações líquidas: uma análise para os estados brasileiros. Dissertação (Mestrado em Economia) - Universidade Federal do Ceará, Fortaleza, 2017.

NEPOM - Núcleo de Estudos de Política Monetária. De 1999 a 2014: O que houve com o câmbio brasileiro? (2014). Disponível em: <https://nepom.wordpress.com/2014/04/24/de-1999-a-2014-o-que-houve-com-o-cambio-brasileiro/>. Acesso em: 20 de ago. 2019.

PASCHOALINO, P. A. T.; CALDARELLI, C. E.; PARRÉ, J. L. Taxa de câmbio e renda externa como determinantes da balança comercial de produtos básicos no estado do Paraná - 2000 a 2015. Revista de Economia, v. 43, n. 2 (ano 40), mai./ago. 2016.

PIAS, D. A sustentabilidade da política fiscal do Rio Grande do Sul: Uma análise de 1970 a 2015. 2017. Disponível em: <http://repositorio.furg.br/handle/1/7592>. Acesso em: 26 de dez. 2019.

RAMALHO, H. M. B.; TARGINO, I. A evolução das exportações brasileiras de cacau: uma análise do período de 1950 a 2000. In: WORKSHOP REDENORDESTE RECORTES SETORIAIS DA ECONOMIA NORDESTINA, 1., 2003, João Pessoa. Anais... João Pessoa: EBAH, 2003.

RISCO, G. R. M., As exportações gaúchas em 2013. Indicadores Econômicos - IEE. Porto Alegre, v. 41, n. 4, p. 6370, 2014.

SACCARO, A.; ALVIM, A. M. Análise das exportações gaúchas, de acordo com a intensidade tecnológica, mediante um modelo VAR. Indic. Econ. FEE, Porto Alegre, v. 44, n. 3, p. 61-78, 2017.

SIMS, C. A. Macroeconomics and reality. Econometrica, New York, v. 48, n. 1, p. 1-48, 1980.

STOCK, J. H. 1994. Unit roots, structural breaks and trends. Handbook of econometrics, 4:2739-2841. Disponível em: <https://doi.org/10.1016/S15734412(05)80015-7>. Acesso em: 28 dez. 2018.

ZIANI, F. V. Propensão de curto e de longo prazo da taxa de câmbio efetiva real sobre as exportações brasileiras

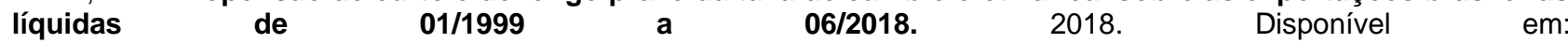
<https://repositorio.ufsm.br/bitstream/handle/1/16320/Ziani_Francine_Vanessa_2018_TCC.pdf?sequence=1\&isAllowed= y>. Acesso em: 25 mai. 2019. 
